"Mircea cel Batran" Naval Academy Scientific Bulletin, Volume XIX - 2016 - Issue 2 The journal is indexed in: PROQUEST I DOAJ / Crossref / EBSCOhost / INDEX COPERNICUS / DRJI / OAJI I JOURNAL INDEX I I2OR / SCIENCE LIBRARY INDEX / Google Scholar / Academic Keys/ ROAD Open Access I Academic Resources / Scientific Indexing Services / SCIPIO / JIFACTOR

\title{
CALCULATION OFDRAG FORCE OF TYPE 22 FRIGATE USING PTC MATHCAD PROGRAM
}

\author{
Andra NEDELCU ${ }^{1}$ \\ Alecu TOMA ${ }^{2}$ \\ ${ }^{1}$ Eng. „Mircea cel Batran” Naval Academy, Constanța, România, andra.nedelcu@anmb.ro \\ 2 Eng. PhD, „Mircea cel Batran” Naval Academy, Constanța, România, alecu.toma@anmb.ro
}

\begin{abstract}
One of the basic problems of design, construction and operation of the ship is about ensuring the evolutionary qualities. This qualities depend largely on hydro and aerodynamic forces acting on the ship`s body and its movement which oppose.

The theme of the study is to calculate the drag force of a ship caused by the waves, the wind, and also the ship towing power calculation, power efficiency propeller, and propeller machine. The specific characteristics of the ship belong to frigates class type 22. The calculation for case study was executed in Mathcad program.
\end{abstract}

Key words: drag, frigate, Froude number, wave, wind.

\section{Introduction}

A ship should be designed to move efficiently through the water with a minimum of external forces which oppose.

Over a ship, moving through water at a certain speed, act the following categories of forces:

- gravity forces, whose resultant is $\overline{F_{g}}$ for size $\Delta$;

- hydrostatic pressure forces whose resultant is $\overline{F_{p}}$ for size $\mathrm{\gamma V}$;

- hydrodynamic forces;

- inertial force $\overline{F_{i}}$ of mass vessel and entrained water moving determined by the speed variation in time;

- thrust force $\bar{T}$ of propellant (for motor vessels) or traction of cable trailer (for towed vessels).

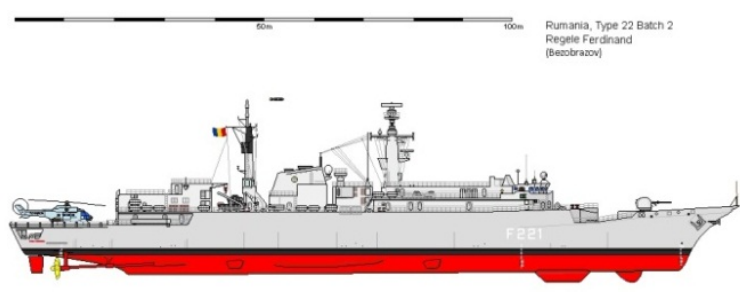

Figure 1. Frigate type 22

\section{Initial data}

The vessel used in the simulation, as a model, is a frigate type 22. Main characteristics of this ship are presented in table 1.

Tabel 1. Main characteristics of the 22 frigate

\begin{tabular}{|l|l|}
\hline Length overall & $L_{W L}=137.6 \mathrm{~m}$ \\
\hline Beam & $B_{W L}=14.75 \mathrm{~m}$ \\
\hline
\end{tabular}

\begin{tabular}{|l|l|}
\hline Draught & $T_{W L}=4.48 \mathrm{~m}$ \\
\hline Displacement & $\Delta=5300$ tons \\
\hline Abscissa center hull & $x_{\text {EWL }}=3.934 \mathrm{~m}$ \\
\hline
\end{tabular}

Another initial data used for simulation are:

- the ratio between length and width:

$$
L_{W L} / B_{W L}=9.329 \mathrm{~m}
$$

- the ratio between beam and draught:

$$
B_{W L} / T_{W L}=3.292 \mathrm{~m}
$$

- the relative abscissa of hull center:

$$
\frac{100 \cdot x_{B W L}}{L_{W V L}}=2.859
$$

- the ratio between length and volume:

$$
\left(\frac{L_{W L}}{v^{\frac{1}{3}}}\right)=65.583
$$

- block coefficient of hull:

$$
C_{B}=0.52
$$

- the longitudinal prismatic coefficient of finesse hull:

$$
C_{L P}=0.69
$$

- additional roughness coefficient:

$$
C_{A R}=0.3 \times 10^{-a}
$$

- gravitational acceleration:

$$
g=9.81 \mathrm{~m} / \mathrm{s}^{2}
$$

- the correction coefficient for pressure resistance represent the ratio between beam and draught of the vessel at buoyancy:

$$
\begin{gathered}
\delta C_{P 1}=0.12\left(\frac{B_{W L}}{T_{W L}}-2.5\right) \cdot 10^{-3} \\
\delta C_{P 1}=9.509 \times 10^{-5}
\end{gathered}
$$

- the correction coefficient for pressure resistance to the geometrical shapes of cross sections of the extremities:

$$
\delta C^{-\infty}=-0.1 \times 10^{-3}
$$

- resistance correction coefficient of friction, wetted surface curve: 
"Mircea cel Batran" Naval Academy Scientific Bulletin, Volume XIX - 2016 - Issue 2 The journal is indexed in: PROQUEST I DOAJ / Crossref / EBSCOhost / INDEX COPERNICUS / DRJI / OAJI I JOURNAL INDEX I I2OR / SCIENCE LIBRARY INDEX / Google Scholar / Academic Keys/ ROAD Open Access I Academic Resources / Scientific Indexing Services / SCIPIO I JIFACTOR

$$
k_{C}=1.025
$$

\section{Case study}

We will determine the drag force parameters using Mathcad PTC program [5]. In practice, the main drag force, $R_{i, i} i=\overline{1_{x} q}$ is determined corresponding to a range of speeds, $v_{i}, i=\overline{1}, q$, which includes the speed required by the design theme.

Determination of the main drag force is based on the equation (13):

$$
R=C_{R} \cdot \frac{p-w_{1}^{2}}{2} \cdot S[k N]
$$

where:

$$
C_{R}=C_{F}+C_{P}=C_{F}+C_{W}+C_{P V}
$$

$S=L_{W L} \cdot T_{W L} \cdot\left(1.36+1.13 \cdot C_{B} \times \frac{B_{W L}}{T_{W L}}\right)\left[\mathrm{m}^{2}\right]$

$C_{R}$ - coefficient for main drag force;

$S-$ thesurface of the wetted hull, using Munaghan 's formula;

$C_{P}-$ coefficient of friction resistance of the hull;

$C_{p}-$ coefficient for pressure resistance.

We introduce in Mathcad the following relation:

- Reynolds number:

$$
R_{e i}=\frac{V_{i}-L_{W L L}}{v}
$$

- resistance friction coefficient of plate smooth equivalent:

$$
C_{F O \mathrm{i}}=\frac{0.075}{\left(\log \left(R \theta_{\mathrm{i}} \mathrm{j}\right)-2\right)^{2}}
$$

- resistance friction coefficient of the hull:

$$
C_{F 1 \mathrm{i}}=k_{C} \cdot C_{F O \mathrm{i}}+C_{A R}
$$

- Froude number:

$$
F r_{1}=\frac{v_{i}}{\sqrt{g L_{W L}}}
$$

- the difference of relative abscesses

$$
\text { difere }_{\mathrm{i}}=\frac{100 x_{\text {BWL }}}{L_{W L L}}-\text { Abscisa }_{\mathrm{i}}[\%]
$$

- correction for the position of the center of hull length:

$\delta C_{P 2 \mathrm{i}}=a \cdot\left(3.355 \cdot F r_{\mathrm{i}}-0.6\right) \cdot$ difere $_{\mathrm{i}} \times 10^{-3}$

Using the relation (21), the correction for vessel shape is:

$$
\delta C_{\text {pai }}=\delta C_{\text {pai }}+\delta C_{\text {pai }}
$$

The coefficient of pressure resistance is:

$$
C_{P i}=C_{P S d i}+\delta C_{P i}+\delta C_{P 2 i}+\delta C_{P a i}
$$

Using the relations (18), (23), we determinate the coefficient for main drag force:

$$
C_{\text {Ri }}=C_{\text {Fi }}+C_{p i}
$$

The main drag force result from (15), (24):

$$
R_{\mathrm{i}}=C_{R \mathrm{i}} \cdot \frac{\rho v_{\mathrm{i}}^{2}}{2} \times S[\mathrm{kN}]
$$

The resistance due to appendices, where $\mathrm{C}_{\mathrm{AP}}=0.25 \cdot 10^{-\mathrm{a}}$ :

$$
R_{\text {LAP }}=C_{A P} \cdot \frac{\rho v_{i}^{2}}{2} \cdot S[k N]
$$

The drag force generated by waves, where $\mathrm{C}_{\mathrm{WM}}=0.4 \times 10^{-\mathrm{a}}$ is :

$$
R_{\mathrm{IVM}}=C_{V M} \cdot \frac{\rho-v^{2}}{2} \cdot S[k N]
$$

The drag force generated by the wind, where $\mathrm{k}_{\mathrm{aer}}=0.02$ is:

$$
R_{\text {AAi }}=k_{\text {aEY }} \cdot R_{\mathrm{i}}[k N]
$$

Using relations (26), (27), (28), the supplementary resistance force is:

$$
R_{\text {Si }}=R_{\text {iAP }}+R_{\text {iVM }}+R_{\text {AAi }}[k N]
$$

The total dragforce is:

$$
R_{T i}=R_{\mathrm{i}}+R_{S i}[k N]
$$

Power towing vessel using (30) is:

$$
P_{E i}=R_{T i} \times v_{i}[k W
$$

\begin{tabular}{|c|c|c|c|c|c|}
\hline & 5 kts & $7 \mathrm{kts}$ & $10 \mathrm{kts}$ & $15 \mathrm{kts}$ & $20 \mathrm{kts}$ \\
\hline$v$ & 2.57 & 3.598 & 5.14 & 7.71 & 10.28 \\
\hline$R_{\mathrm{mi}}$ & $3.041 \times 10$ & $4.257 \times 10$ & $6.081 \times 10$ & $9.122 \times 10$ & $1.1216 x$ \\
\hline$C_{\mathrm{Fpi}}$ & $1.784 \times 10$ & $1.707 \times 10$ & $1.63 \times 10$ & $1.548 \times 10$ & $1.494 \times 1$ \\
\hline$C_{\mathrm{mi}}$ & 2129 & $2.049 \times 10$ & $1.97 \times$ & $1.887 \times 10$ & $1.831 \times 1$ \\
\hline$F r_{2}$ & 0.07 & 0.098 & 0.14 & 0.21 & 0.28 \\
\hline$C_{\text {ges }}$ & $0.25-10^{-2}$ & $0.48-10^{-2}$ & $1.49 \cdot 10^{-2}$ & $2.25 \cdot 10^{-2}$ & $3.25-10^{\prime}$ \\
\hline Abscis & 1 & 1 & 2 & 22 & 2.5 \\
\hline dififere & 1.859 & 1.859 & 0.859 & 0.659 & 0.359 \\
\hline $6 C_{p z i}$ & $-5.093 \times$ & $-3.785 x$ & $-8.416 x$ & $5,143 \times 10$ & $9.121 \times 1$ \\
\hline $6 C_{p z i}$ & $-1 \times 10^{-4}$ & $-1 \times 10^{-4}$ & $-1 \times 10^{-4}$ & $-1 \times 10^{-4}$ & $-1 \times 10^{-3}$ \\
\hline$C_{p i}$ & $-2.643 x$ & $9.663 \times 1$ & $1.401 \times 1$ & $2297 \times 1$ & $3.336 \times 1$ \\
\hline$C_{R i}$ & $1.865 \times 1$ & $2.146 \times 1$ & $3.371 \times 1$ & $4,183 \times 1$ & $5.168 \times 1$ \\
\hline$R_{i}$ & 1282 & 28.916 & 92708 & 258.844 & 568.438 \\
\hline$R_{\text {lay }}$ & 1.719 & 3.369 & 6.875 & 15.468 & 27.499 \\
\hline$R_{\text {Syse }}$ & 275 & 5.39 & 11 & 24749 & 43.999 \\
\hline$R_{\text {A.Ai }}$ & 0.256 & 0.578 & 1.854 & 5.177 & 11.369 \\
\hline$R_{s i}$ & 4725 & 9.337 & 19.729 & 45.395 & 82.867 \\
\hline$R_{\pi i}$ & 17.546 & $38.253 k$ & 112437 & 304.238 & 651.304 \\
\hline$P_{\text {In }}$ & 45.092 & 137.6348 & 577.9270 足 & $234568 \times$ & 6.69541 \\
\hline
\end{tabular}

Using relation (30), we determinate:

- the power of the propeller: $P_{D i}=\frac{1.36 R_{T i} T_{i}}{\eta_{D}}$ [CP] (32), where the efficiency propeller is $\eta_{D}=0.6$.

- the power on the axis of the propeller: $P_{B i}=\frac{1, a 6 R_{T i}^{2} V_{i l}^{i}}{\eta_{D} \eta_{s}}[C P]$ (33), where the efficiency propeller axis is $\eta_{s}=0.97$.

- the effective power to the main machine

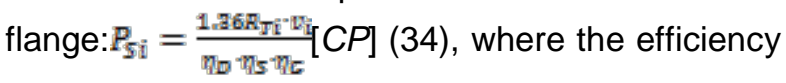
reversing device and reduced rotational speed is $\eta_{G}=0.9$.

- the power indicated on the main machine: $P_{i i}=\frac{1.36 R_{T i} v_{i}}{\eta_{D} \cdot \eta_{S} \eta_{G} \eta_{M}}[\mathrm{CP}](35)$, where the machine's mechanical efficiency is $\eta_{M}=0.8$.

The results for different value of speed, are systematically presents in table 2 .

Table 2 Results using Mathcad PTC[5] 
"Mircea cel Batran" Naval Academy Scientific Bulletin, Volume XIX - 2016 - Issue 2

The journal is indexed in: PROQUEST I DOAJ / Crossref / EBSCOhost / INDEX COPERNICUS / DRJI / OAJI I

JOURNAL INDEX / I2OR / SCIENCE LIBRARY INDEX / Google Scholar / Academic Keys/ ROAD Open Access I Academic Resources / Scientific Indexing Services / SCIPIO I JIFACTOR

\begin{tabular}{|l|l|l|l|l|l|}
\hline$P_{D i}$ & 102.208 & 311.972 & $1.31 \times 10^{2}$ & $5.317 \times 1$ & $1.518 \times 1$ \\
\hline$P_{n i}$ & 105.37 & 321.621 & $1.35 \times 10^{2}$ & $5.481 \times 10$ & $1.565 \times 1$ \\
\hline$P_{s i}$ & 107.52 & 328.185 & $1.378 \times 10$ & $5.593 \times 10$ & $1.596 \times 1$ \\
\hline
\end{tabular}

\begin{tabular}{|l|l|l|l|l|l|}
\hline$P_{\overline{\text { Ii }}}$ & 134.4 & 410.231 & $1723 \times 10$ & $6.991 \times 10$ & $1.996 \times 1$ \\
\hline$\eta_{p}$ & 0.456 & & & \\
\hline
\end{tabular}

\section{CONCLUSION}

The drag force of a ship depends on her velocity. Therefore, drag force is always specified at a particular velocity. Furthermore, we understand that the drag will depend on the condition of the sea. We cannot expect that the drag force of a ship in a rough sea to be the same as the drag force of the ship in a calm sea. Also, operating conditions for ship must be specified. Therefore, drag force of a ship is defined as the force required towing the ship in calm water at a constant velocity.

The table 2 shows that at a slow or medium speed of frigate, the wavemaking resistance is small compared with frictional resistance. At high speeds, the wavemaking resistance increases and can be $50-60 \%$ of total drag force.

An additional resistance, which may be considerable, is the wind force acting on the ship's body. Even is a small resistance component, it is important because it could influence the aerodynamic shape.

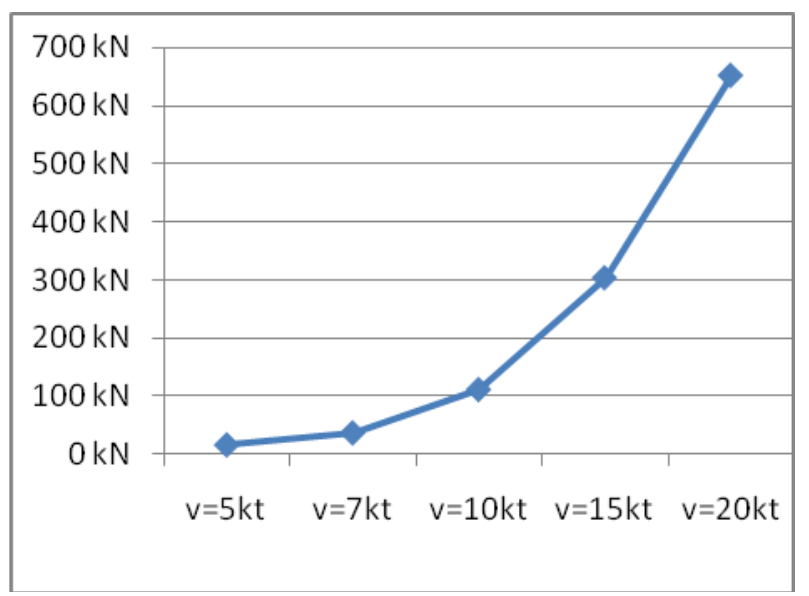

Figure 2 The graphic of total resistance of the frigate

Using the relation (31), thefigure 2, shows that for a speed of 5 or 7 knots, the variation oftotal drag forceis not major. Starting with 13 knots speed, the resistanceforce is tripled, reaching 30 times higher.

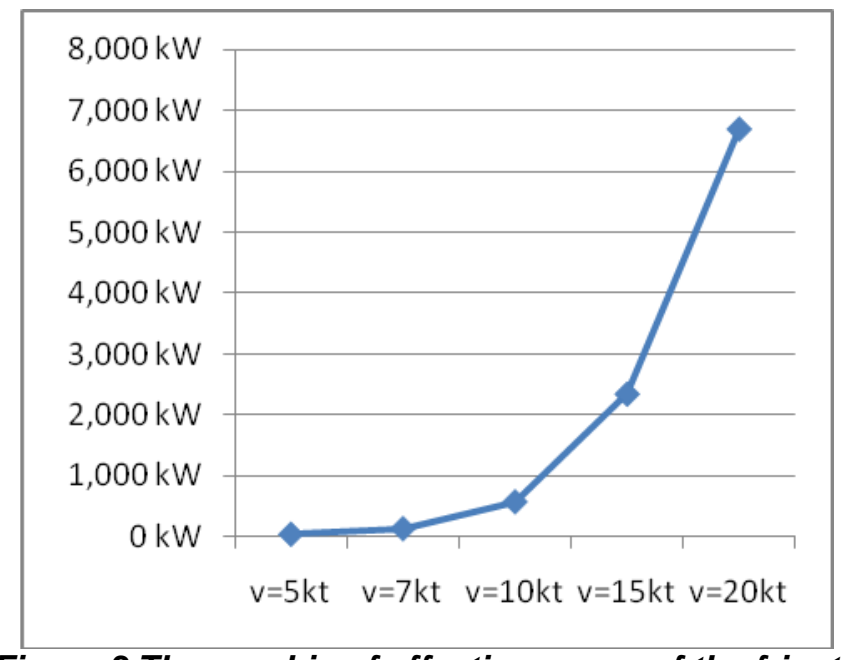

Figure 3 The graphic of effective power of the frigate

The drag force variation caused by the variation of the speed, waves, the wind etc., further lead to a change in the propeller's speed and, consequently, the drive power[3].Figure 3 shows a different value of power for different value of speed. For example, for 5 knots, the power used is $45 \mathrm{~kW}$, but once we increase the speed (for 10 knots we have $570 \mathrm{~kW}$ ), the power increases too. This is the reason that the ship's propulsion system 
"Mircea cel Batran" Naval Academy Scientific Bulletin, Volume XIX - 2016 - Issue 2 The journal is indexed in: PROQUEST I DOAJ / Crossref / EBSCOhost / INDEX COPERNICUS / DRJI / OAJI I JOURNAL INDEX I I2OR / SCIENCE LIBRARY INDEX / Google Scholar / Academic Keys/ ROAD Open Access I Academic Resources / Scientific Indexing Services / SCIPIO / JIFACTOR

should be adapted to these changes in load because once increased the speed of frigate, the power of towing, the power of propeller and machine increase too.

This type of calculation of the drag force of a ship is necessary for choose the drive motor and the main elements of the axial line.

\section{BIBLIOGRAPHY}

[1] V. Maier, Mecanica si constructia navei, Editura Tehnica

[2] C. Năstase, Calculul și construcția navei, Editura Didactica și Pedagogică, București, 1964

[3] G. Kuiper, Resistance and Propulsion of Ships, Technical University Delft, 1991

[4] J. Holtrop, A Statistical Re-Analysis of Resistance and Propulsion Data, International Shipbuilding Progress, 1984

[5] PTC Mathcad program 